\title{
El producto turístico comunitario como estrategia para diversificar las economías locales del cantón Bolívar, provincia de Manabí, Ecuador
}

\section{The community tourism product as a strategy to diversify the local economies of Bolivar Canton, Manabi Province, Ecuador}

Nelson García Reinoso ${ }^{1}$ Neme Yamil Doumet Chilan²

Resumen: El objetivo de este trabajo es el diseño de un producto turístico comunitario (PTC) para la diversificación de las economías locales del cantón Bolívar, provincia de Manabí, Ecuador, cuyo fin es contribuir al desarrollo de las comunidades de Cabello, Sarampión, Chapulí, Primera Piedra, Julián y la Esperanza. La metodología propuesta se fundamenta en la revisión de la literatura y se ajusta a las Fichas de Inventario Turístico del Ecuador (2008) y el Plan de Ordenamiento Territorial del cantón Bolívar (2011). La base de este trabajo fue el diagnóstico turístico situacional y la recopilación de información se basó en las dimensiones social, económica, política e institucional. Se realizó una valoración de la gestión turística mediante la aplicación de la matriz DAFO para identificar estrategias dirigidas a la potencialización de los recursos naturales y culturales que caracterizan el área objeto de estudio. Se realizó un estudio de mercado para conocer la oferta y la demanda actual y potencial. La estructuración del PTC se sustentó en dos rutas turísticas que integran a seis comunidades que forman parte del cantón Bolívar y el diseño del mismo define las estrategias de comercialización y promoción. Una importante conclusión es que la implementación del PTC permite el aprovechamiento de las potencialidades turísticas del cantón Bolívar y por ende tributa al desarrollo turístico local de sus comunidades.

Palabras clave: Producto turístico comunitario, gestión turística, desarrollo local.
Abstract: The objective of this work is to design a community tourism product (CTP) for the diversification of the local economies of Bolivar Canton, Manabi Province, Ecuador, the goal of which is to contribute to the development of the communities of Cabello, Sarampión, Chapulí, Primera Piedra, Julián and la Esperanza. The proposed methodology is based on a literature review and is adapted to the Ecuadorian Tourist Inventory Sheets (2008) and the Land Use Plan for the Bolivar Canton (2011). The basis of this work was the situational tourist diagnosis and the data collection was based on social, economic, political and institutional dimensions. Tourism management was assessed by applying a SWOT analysis to identify strategies that could maximize the natural and cultural resources that characterize the study area. A market study was performed to learn about the current and potential supply and demand. The structuring of the CTP was sustained on two tourist routes that integrate six communities in the Bolivar Canton and its design defines the marketing and promotion strategies. An important conclusion is that the implementation of the CTP can harness the tourism potential of the Bolivar Canton and therefore contribute to the development of local tourism in its communities.

Keywords: Community tourism product, tourism management, local development.

(Presentado: 05 de diciembre de 2016. Aceptado: 2 de febrero de 2017)

\footnotetext{
1 Ingeniero Industrial. Master en Gestión Turística en la Universidad Central Marta Abreu de Las Villas, Cuba. Docente universitario de la Escuela Superior Politécnica Agrope cuaria de Manabí Manuel Félix López ESPAM MFL, Ecuador.

2 Licenciado en Turismo en la UNIRONDON Brasil. Magister en Planificación de Proyectos Turísticos Ecológicos, Universidad Agraria del Ecuador. Docente investigador de la ESPAM-MFL, Ecuador.
} 


\section{INTRODUCCIÓN}

La Federación Plurinacional de Turismo Comunitario del Ecuador (FEPTCE, 2013), miembro del Consejo Consultivo del Ministerio de Turismo (MINTUR), considera al turismo comunitario en la visión de las propias comunidades, que buscan la construcción de un verdadero turismo intercultural, donde sus miembros participen activamente, garanticen el manejo adecuado de los recursos naturales, la valorización de sus patrimonios, derechos culturales y territoriales de los pueblos y nacionalidades permitiendo la redistribución equitativa de los beneficios generados.

Se menciona que la actividad turística enfocada al turismo comunitario es una estrategia social, que ha permitido generar ingresos y crear una oportunidad de fomentar empleos, sumando nuevas actividades económicas a los pueblos del Ecuador. Esto representa un apoyo para frenar la migración rural, mejorar la calidad de vida, preservar la arquitectura de los pueblos tradicionales, la cultura, el desarrollo sostenible y la participación activa de los grupos sociales, características inseparables del turismo comunitario. Esta actividad tiene un enfoque diferente porque no solo busca utilidades económicas, sino también el bienestar de los involucrados que muchas veces sustituye el papel del Estado al proveer a la comunidad de servicios básicos como la salud y la educación que son escasos en el sector rural del Ecuador.

En el ámbito latinoamericano se señala al Ecuador como un país pionero en turismo comunitario. De acuerdo con Ruiz et al. (2007) desde los años 80 este tipo de turismo se ha convertido en una actividad estratégica vinculada al ecoturismo; tomó fuerza a partir del 2000, año en que también surge la necesidad de legalizarla. Jurados (2012) menciona que el turismo comunitario se refiere a aquel turismo que está basado en la comunidad local y que pretende reducir el impacto negativo y reforzar los impactos positivos del turismo en la naturaleza. Se configura como una herramienta de lucha contra la pobreza, que permite conservar el patrimonio natural, histórico y la identidad étnica de un destino turístico. El turismo comunitario hace referencia a "aquel tipo de turismo en el que la comunidad local tiene un control sustancial de, y participa en, su desarrollo y manejo, y una importante proporción de los beneficios se quedan en la comunidad”. Por su parte, Orgaz (2013) plantea que el turismo comunitario busca me- jorar la situación socioeconómica y conservar los recursos naturales del territorio a través del contacto establecido entre la comunidad local y el turista. Diversos autores sugieren que el turismo comunitario es la integración y el oportuno equilibrio entre las oportunidades de un adecuado manejo de los recursos naturales y culturales y de la apreciación que se tenga del patrimonio cultural, sustentado en la equidad proporcionada del beneficio obtenido tanto para la comunidad como para el mismo turista. Para Maldonado (2006), el turismo comunitario manifiesta principios que se detallan de la siguiente manera:

- Social, ya que busca promover una efectiva cooperación entre los miembros de la comunidad y entre comunidades, en la distribución equitativa de las oportunidades y los beneficios que genera la actividad turística.

- Ambiental, esto es ambientalmente responsable ya que busca fomentar la conciencia respetuosa y formas de gestión responsable; lo que persigue es fomentar la conciencia respetuosa y formas de gestión sustentable de los recursos naturales y de la biodiversidad creando así vínculos para defender los derechos de las tierras y los territorios ancestrales.

- Económico, porque busca incorporar objetivos de gestión en el uso y valoración de los recursos que se movilizan, buscando así beneficios que permiten remunerar el trabajo y las inversiones que se realizan.

- Cultural, porque propicia experiencias y encuentros interculturales de calidad entre los turistas y las comunidades, respetando las expresiones de la identidad cultural.

En el turismo comunitario la puesta en valor del patrimonio natural, cultural, social, arquitectónico y gastronómico de la pequeña localidad es preponderante, entendiendo que son ellos los valores distintivos del mismo, aquellos que los hacen "únicos" y por los cuales la demanda busca conocerlos. El turismo comunitario significa turismo responsable, en el respecto del medio ambiente y de la sensibilidad de la comunidad que unido al visitante mantienen un comportamiento responsable. 
La temática del estudio se manifiesta en torno a la creación de productos turísticos, dentro del contexto que abarca el turismo comunitario es una actividad que se refiere a que la comunidad local, debe ejercer un rol sustancial y participativo en todo el proceso y que por consiguiente una importante proporción de los beneficios quedará en la comunidad. Los producto pueden ser objetos físicos, servicios, personas, lugares, organizaciones, ideas, instituciones; los cuales poseen cualidades físicas relacionadas con la calidad intrínseca, la marca, el envase, el diseño, etc. Además de otras cualidades intangibles relacionadas con los servicios de mantenimiento, garantía, asesoramiento y cualidades sicológicas asociadas a la imagen/ posicionamiento, el factor humano, la calidad percibida o capacidad del producto para satisfacer las expectativas del cliente / comprador. El producto turístico se define como cualquier cosa que se puede ofrecer a un mercado para la atención, la adquisición, el uso o el consumo que podría satisfacer un deseo, o una necesidad. Incluye objetos físicos, servicios, sitios, organizaciones e ideas. Esto muestra la importancia que ha adquirido esta forma de turismo en los destinos, y su posterior estudio por parte de la comunidad científica. Además evidencia el proceso de potenciación de las comunidades locales que se están desarrollando en los últimos años en países subdesarrollados mediante el turismo comunitario. Es decir, la cultura, el patrimonio y los recursos naturales locales están siendo usados por las comunidades locales para mejorar el desarrollo socioeconómico del destino.

Se reconoce también que Ecuador ha experimentado dificultades para viabilizar con éxito proyectos de turismo comunitario. Esto se debe a factores relacionados con las complejas relaciones sociales al interior de la comunidad, a la débil organización comunitaria, al escaso o nulo conocimiento de la administración del negocio, al no tener acceso a información, carecen de recursos técnicos y financieros para configurar la estructura empresarial requerida para el mejoramiento de las operaciones de los proyectos turísticos.

Dentro del territorio del cantón Bolívar, provincia de Manabí, Ecuador, se observan comunidades que poseen una amplia gama de atractivos y recursos turísticos naturales y culturales; los pobladores mantienen tradiciones propias de la zona, pero en su mayoría del territorio la economía se basa en la agricultura, ganadería y pesca, no aprovechándose las potencialidades turísticas que lo caracterizan y que constituyen un pilar básico para su desarrollo económico.

El producto de turismo comunitario (PTC) propuesto busca promover el desarrollo en las comunidades de Cabello, Sarampión, Chapulí, Primera Piedra, Julián, y la Esperanza, dentro del cantón Bolívar. La elaboración y estructura del PTC se conforma de dos rutas turísticas que integran seis comunidades del cantón Bolívar. La ruta número uno está destinada al referente cultural, la misma que se estructura por la combinación de dos comunidades (Cabello y San Miguel de Sarampión). Esta ruta ofrece diversos servicios donde se destaca la gastronomía manabita, servicios de hospedaje y otras actividades como el senderismo, exposición de ferias gastronómicas, y festivales. La segunda ruta está destinada básicamente al aprovechamiento del turismo de naturaleza, la misma se encuentra estructurada por cuatro comunidades (La Esperanza, Cascada Chapuli, Cascada Julián y Primera Piedra), asociada al referente natural en donde se puede disfrutar de la variedad de paisajes naturales interesantes y platos típicos. El diseño del PTC propuesto está direccionado al desarrollo turístico de las comunidades del cantón Bolívar, abriendo el campo del turismo como eje principal para el mejoramiento de la calidad de vida de los habitantes. El diagnóstico turístico arrojó la necesidad de elaborar productos que revaloricen y proyecten los recursos turísticos existentes en la zona rural del cantón.

\section{MATERIALES Y MÉTODOS}

La investigación se efectuó en el cantón Bolívar, provincia de Manabí, Ecuador. Para la elaboración del PTC se analizaron y utilizaron seis metodologías en base a lo reportado por el Ministerio de Comercio Exterior y Turismo y la Comisión de Promoción del Perú para la Exportación y el Turismo (MINCETUR y PROMPERU, 2014), MINTUR (2003), Blanco (2008), Machado-Hernández (2007) y Machado (2013). Además del aporte brindado por la literatura se utilizó el Manual de Inventario Turístico del MINTUR (2004), las Fichas de Inventario Turístico del Ecuador (2008), el Plan de Ordenamiento Territorial del cantón Bolívar (2011) y el Manual de diagnóstico turístico local de Ricaurte (2009). La metodología propuesta consta de tres fases que se detallan en la tabla 1. 
TABLA 1. Metodología para el diseño de un producto turístico comunitario en el cantón Bolívar.

\begin{tabular}{llcc}
\hline \multicolumn{1}{c}{ Fases } & \multicolumn{1}{c}{ Etapas } & Actividades & Técnicas e instrumentos \\
\hline $\begin{array}{l}\text { 1. Diagnóstico turístico } \\
\text { situacional del } \\
\text { cantón Bolívar }\end{array}$ & $\begin{array}{l}\text { 1. Caracterización y } \\
\text { delimitación del área } \\
\text { objeto de estudio }\end{array}$ & $\begin{array}{c}\text { 1. Descripción de la situación } \\
\text { actual y caracterización servicios } \\
\text { básicos e infraestructura. } \\
\text { 2. Inventarios de los } \\
\text { recursos turísticos. }\end{array}$ & $\begin{array}{c}\text { Descriptivo, investigación } \\
\text { de campo, entrevista } \\
\text { dirigida. }\end{array}$ \\
& $\begin{array}{l}\text { 2. Inventario de los } \\
\text { recursos turísticos }\end{array}$ & $\begin{array}{c}\text { 3. Recopilación y registro } \\
\text { de información. }\end{array}$ & Ficha de inventario, \\
& & $\begin{array}{l}\text { 1. Identificación de } \\
\text { la oferta turística. }\end{array}$ & \\
& 3. Análisis de la oferta potencialidades. \\
& competitiva & 2. Elaboración del \\
& perfil competitivo. & Observación científica, \\
& & matriz de potencialidades, \\
& & matriz de perfil competitivo.
\end{tabular}
2. Estudio de
mercado
4. Análisis de
la demanda

5. Análisis situacional

3. Diseño, estructura y comercialización del producto turístico comunitario
3. Análisis de la encuesta

4. Caracterización del perfil del cliente y

Segmentación de mercado.

5. Elaboración matriz FODA.

6. Identificación de estrategias.

1. Diseño de las rutas.

6. Diseño del Producto.

2. Descripción de las rutas

3. Elaboración de los paquetes turísticos

7. Definición del precio

4. Confección de fichas de costos.

6. Estrategias de posicionamiento

7. Estrategias de comercialización
Encuestas, entrevistas libres.

Tormenta de ideas, observación científica y matriz FODA.

Entrevistas, tormenta de ideas.

Ficha de costos, tormenta de ideas. Observación directa, tormenta de ideas.

Fuente: Elaboración propia.

\section{Fase 1. Diagnóstico turístico}

\section{situacional del cantón Bolívar}

En esta primera fase se realizó una caracterización y delimitación del área objeto de estudio mediante una recopilación de información de los factores ambientales y socio culturales, se desarrollaron visitas de campo, encuestas y entrevistas, se utilizó el método deductivo, analítico sintético y de observación directa. Se utilizaron fichas de diagnóstico y de inventario turístico propuestos por el MINTUR (2004), en el estudio del diagnóstico se elaboró y actualizó el inventario de recursos turísticos del cantón Bolívar en donde se pudo observar la potencialidad turística existente.

\section{Fase 2. Estudio de mercado}

El estudio de mercado busca focalizar y determinar la oferta y la demanda potencial dentro de lo que corresponde el turismo comunitario dentro del cantón Bolívar. Los resultados obtenidos mediante este análisis permitieron plantear varias estrategias de promoción y marketing. Se realizó un análisis de la demanda que tuvo como objeto conocer claramente al perfil del visitante y todo lo que respecta a las motivaciones que tengan en cuanto al turismo comunitario. Se procedió a la aplicación de 240 encuestas; la muestra tomó como referencia la población del cantón Bolívar que según datos del Instituto Nacional de Estadísticas y Censos (INEC, 2010) posee una población de 40.735 habitantes de los cuales 7.735 corresponden al área rural y 33.000 al área urbana. El estudio de la demanda se realizó a través del uso de una encuesta que incluyó las principales variables relacionadas con productos 
turísticos en las condiciones del área de estudio. Se llevó a cabo la determinación del tamaño de muestra, tomando en cuenta lo planteado por Aguilar (2005), siguiendo un criterio estadístico y asumiendo una población finita, según la siguiente ecuación:

$$
n=\frac{N \times z^{2} \times p \times q}{e^{2} \times(N-1)+z^{2} \times p \times q}
$$

Para la determinación de la muestra se fijó un nivel de confianza del 95\% $(z=1,96)$, varianza máxima $(p=q=0,5)$ y se estimó un margen de error del 10\% $(e=0,1)$. En la aplicación de las encuestas se utilizó un muestreo probabilístico aleatorio simple. De manera progresiva se concluye el análisis con la realización de la matriz FODA que determinó las Fortalezas, Debilidades, Amenazas y Oportunidades de la gestión turística del territorio. A través del empleo de técnicas como la observación científica, tormenta de ideas y entrevistas se procedió al análisis de las fortalezas, oportunidades, debilidades y amenazas relacionadas con el diseño del producto comunitario. Una vez identificados los factores externos e internos que influyen en el análisis, se evaluó el nivel de importancia de cada uno, y se identificaron las estrategias de aprovechamiento de las oportunidades existentes y minimización de debilidades.

\section{Fase 3. Diseño, estructura y comercialización del PTC propuesto}

Esta fase detalla toda la estructura que conlleva la elaboración de un PTC y se mencionan todas las herramientas utilizadas para la toma de decisiones acertadas, ya sea tanto para la elaboración, estructura y comercialización tomando como base los estudios anteriores (diagnóstico, inventario turístico y estudio de mercado). Se estructura y se pone en práctica el circuito diseñado de acuerdo a las características de los consumidores identificados. Para esto se utilizaron técnicas y herramientas relacionadas con la comercialización de productos y servicios con la inserción del circuito propuesto en el mercado turístico y en armonía con el desarrollo de ofertas turísticas en el cantón Bolívar. En esta etapa se determinaron los canales de difusión de mayor relevancia. Aquí se tomó en cuenta varias alternativas y formas combinadas con métodos tradicionales y actuales para el conocimiento y comercialización del producto, así como un empleo variado y óptimo de diferentes medios como radio, televisión, prensa escrita, comunicación personal, relaciones públicas, redes sociales, Website y folletos promocionales.

\section{CONCLUSIONES}

La investigación se efectuó en el cantón Bolívar, provincia de Manabí. Para la elaboración del PTC se tomó como punto de partida las comunidades de San Miguel de Sarampión (Finca Sarita), Cabello (Quinta Colina del Sol, Alfareros de Barro), La Esperanza, Las Cascadas de Chapulí y Julián, y Primera Piedra. Estas mismas comunidades ayudaron a la recolección y obtención de datos. Según el Gobierno Autónomo Descentralizado del Cantón Bolívar en su Plan de Desarrollo y Ordenamiento Territorial (2011), menciona que geográficamente el cantón se encuentra ubicado en la parte nororiental de la provincia de Manabí. Su posición gastronómica es de $0^{\circ}, 50$ minutos, 39 segundos de latitud sur y $80^{\circ}, 9$ minutos, 33 segundos de latitud oeste. Limita al norte con el cantón Chone; al sur con Portoviejo, Junín y Santa Ana; al este con el cantón Pichincha y al oeste con Tosagua. El cantón Bolívar cuenta con una extensión territorial de 538 km2. Bolívar presenta una topografía plana en la parte baja por los valles e irregular ondulada y quebrada en la parte alta y montañosa. La altitud es de $21 \mathrm{msnm}$ en la parte baja y de 400 msnm en la parte alta. Políticamente se divide en una parroquia urbana Calceta, ciudad que a la vez es su cabecera cantonal y dos parroquias rurales, Quiroga y Membrillo.

\section{Fase 1. Diagnóstico turístico situacional del cantón Bolívar}

\section{Caracterización del recurso potencial}

Las localidades de San Miguel de Sarampión, Julián, Chapulí, Cabello y la Esperanza están localizadas en un radio de $30 \mathrm{~km}$ aproximadamente de la cabecera cantonal. Se evidencia que existe variedad de ecosistemas y recursos naturales y culturales con potencialidad turística desde el punto de vista rural. Cabe mencionar que para poder acceder a las localidades mencionadas existe determinada accesibilidad por temporadas estacionarias, los medios de transportes usualmente utilizados son la Cooperativa de Transporte Calceta, San Cristóbal, Ciudad de Canuto, y flota de transporte Bolívar. En lo que respecta a la planta turística dentro de las comunidades es inexistente lo que refiere a la restauración es esporádica e inadecuada, lo mismo observado con el hospedaje. Por otra parte se destaca que no existe señalética turística para poder acceder y ubicarse al momento de visitar los atractivos del área rural del cantón Bolívar. 
Inventario de los recursos turísticos del cantón Bolívar

Para el inventario de los recursos turísticos se utilizaron las fichas actualmente vigentes del MINTUR (2004). Se registraron principalmente aquellos recursos de mayores potencialidades, los cuales se muestran en la tabla 2.

\section{TABLA 2. Recursos turísticos - Catastro del cantón Bolívar (2016).}

\begin{tabular}{llll}
\hline Nombre & \multicolumn{1}{c}{ Categoría } & \multicolumn{1}{c}{ Tipo } & \multicolumn{1}{c}{ Subtipo } \\
\hline Finca Orgánica Sarita & Manifestaciones culturales & $\begin{array}{l}\text { Realizaciones técnicas } \\
\text { científicas }\end{array}$ & $\begin{array}{l}\text { Explotaciones y } \\
\text { agropecuarias }\end{array}$ \\
Gastronomía & Manifestaciones culturales & Etnografía & Comidas y bebidas típicas \\
$\begin{array}{l}\text { Paraje Natural y Cultural } \\
\text { "Quinta Colina del Sol” }\end{array}$ & Manifestaciones culturales & Históricas & Museos \\
$\begin{array}{l}\text { Artesanías en Barro } \\
\text { Cascada de Chapulí }\end{array}$ & Manifestaciones culturales & Etnografía & Ríos \\
Cascada de Julián & Sitio natural & Ríos & Artesanías \\
Cascadas Primera Piedra & Sitio natural & Ríos & Cascada \\
Presa La Esperanza & Manifestaciones culturales & Realizaciones técnicas \\
& & y científicas & Cbras técnicas \\
\hline
\end{tabular}

Fuente: Elaboración propia.

\section{Fase 2. Estudio de mercado}

\section{Estudio de la oferta}

El Catastro Turístico de Bolívar muestra datos en donde se da a conocer los servicios de la oferta turística del cantón distribuida de la siguiente manera: En el área de Hospedaje tenemos un total de 8 negocios, dentro de la segunda categoría se registran 5 establecimientos y 3 de tercera categoría. En cuanto a restauración se ubicaron 7 establecimientos de segunda categoría, 2 de tercera categoría y 14 de cuarta categoría. Referente a los centros de diver- sión se dan a conocer 15 establecimientos localizando uno de segunda categoría.

\section{Análisis de la demanda}

En el estudio de la demanda se utilizó como técnica la encuesta, con la aplicación de un cuestionario a personas en diferentes sitios de los anteriormente incluidos en el estudio de la oferta. Con los resultados obtenidos se confeccionó un perfil del cliente con potencial representativo en la demanda, de acuerdo a las características de las dos rutas propuestas. Un resumen se presenta en la tabla 3.

\section{TABLA 3. Perfil del visitante.}

\section{Género}

Edad

Nivel de formación

Ocupación

Ingresos mensuales estimados

Ingresos por cada actividad turística

Acompañamiento

Principal motivo por el que viajan

Medios de información

Actividades preferidas por los turistas
Masculino 45\%, femenino 55\%

20 a 29 años de edad

Superior

Trabajadores

$\$ 500$ a $\$ 1.000$

21 a 30 dólares

Familiares

Turismo y ocio

Ferias turísticas, amigos y familiares, televisión

Alimentación y guías, recorridos a fincas orgánicas

Fuente: Elaboración propia. 


\section{Análisis situacional}

Este análisis tomó en cuenta los elementos internos y externos mediante un análisis FODA relacionado con puntos vinculantes en turismo y desarrollo local.
Se evaluaron las características y potencialidades de los recursos turísticos estudiados. Los resultados se muestran en la tabla 4.

\section{TABLA 4. Análisis FODA del cantón Bolívar.}

\section{Fortalezas}

Facilidad de acceso a los recursos.

Conservación de las tradiciones artesanales en general.

Recursos con potencialidad turística (naturales/culturales).

Clima agradable

Características intangibles de actitud y aptitud para el servicio (amabilidad de los habitantes al momento de recibir a personas de otros lugares, lo cual ayudará en la atención al cliente en los diferentes recursos existentes).

Se conserva la identidad cultural del montubio-manabita por gestores culturales y habitantes del sector rural.

Precios de los productos y servicios accesibles al turista.

Existe variedad de flora y fauna, y una vasta producción agrícola y pecuaria dentro de todo el cantón.

Interés por parte de la población en incursionar en el turismo.

\section{Debilidades}

Desconocimiento de los habitantes de ciertas comunidades con respecto a la potencialidad turística que poseen.

Desestimación por parte de las autoridades competentes en cuanto al potencial turístico existente.

Falta de planificación turística para el desarrollo del sector rural. Deficiencias en los servicios básicos públicos.

Personal sin asesoramiento y conocimiento técnico en el ámbito turístico.

Poca promoción turística por parte del MINTUR. Inexistente señalización vial y turística en zonas rurales. Inexistencia de productos turísticos desarrollados. Inexistencia de infraestructura turística y deficiente vías de acceso a varios sitios de interés.

\section{Oportunidades}

Las nuevas tendencias turísticas direccionadas al turismo comunitario fortalecidas en el PLANDETUR 2020.

Inclusión y fortalecimiento del Turismo Comunitario.

Elaboración de nuevos proyectos enfocados al desarrollo del turismo. Cercanía a la cabecera cantonal Calceta y a otros recursos turísticos. Asociación con la Escuela Superior Politécnica Agropecuaria de Manabí mediante su vinculación con proyectos turísticos.

El aporte que actualmente está brindando el Gobierno Autónomo Descentralizado del cantón en cuanto al turismo.

Importancia de las campañas publicitarias que está proyectando el MINTUR para potencializar el turismo a nivel mundial, nacional y provincial del Ecuador.

Variedad de flota de transportes para acceder a los recursos.

\section{Amenazas}

Vulnerabilidad a riesgos naturales y antrópicos. Incumplimiento de planes de organismos nacionales, provinciales, cantonales y parroquiales.

Competencia potencial.

Inseguridad política y social.

Inadecuado manejo de los recursos por parte de los gestores locales. Inseguridad económica.

Fuente: Elaboración propia.

Tomando en cuenta los elementos analizados se identificaron varias problemáticas fundamentales asociadas a las debilidades detectadas y relacionadas con la gestión turística en el cantón Bolívar. Sobre las cuales se tiene capacidad de actuación y considerando la po- sibilidad de alcanzar un desarrollo sostenible del cantón Bolívar se detallan las siguientes estrategias, sobre los tres ejes de sostenibilidad, basadas en las debilidades del territorio. Las estrategias identificadas se relacionan en la tabla 5 . 
TABLA 5. Estrategias de la matriz FODA.

Estrategia FO

Diseñar planes de revalorización y promoción de los recursos turísticos mediante alianzas con instituciones del cantón Bolívar.

Elaborar productos turísticos que diversifiquen y fomente la actividad turística sostenida.

Estrategia FA

Capacitaciones al personal inmerso dentro de las actividades turísticas.

Elaborar gestiones de desarrollo turístico, en donde se planifique nuevas plazas de empleo con una previa capacitación para que la inestabilidad económica que existe en el cantón se logre disipar en un alto porcentaje.

Realizar un plan piloto en conjunto con el municipio y la universidad con el fin de asesorar en el ámbito turístico al personal competente enmarcado dentro de la aérea turística.
Estrategia DO Determinar campañas de promoción turística del cantón Bolívar en conjunto con el GAD municipal y la universidad con el fin de fortalecer el turismo comunitario y aportar nuevas ideas y estrategias para campañas publicitarias.

Establecer convenios con entidades dedicadas al desarrollo de la investigación en diferentes áreas.
Estrategia DA Mantener relaciones continuas con instituciones especializadas en planificación y promoción turística.
Crear indicadores que mejoren la organización y la competitividad del GAD municipal. Determinar nuevos métodos que mejoren el direccionamiento de la institución.

Fuente: Elaboración propia.

\section{Fase 3. Diseño, estructura y comercialización del PTC propuesto}

EI PTC enfatiza la proyección y la elaboración de dos rutas turísticas enmarcando e identificando el aspecto natural y cultural de los recursos de las localidades de San Miguel de Sarampión, Cabello, Primera Piedra, Chapulí, Julián, La Esperanza. Básicamente las rutas fomentan las actividades recreativas turísticas, específicamente para el mercado y la demanda focalizada, actividades como el senderismo, camping, pesca artesanal, rescate de las tradiciones ancestrales del cantón, practica de juegos populares, y la variedad de la gastronomía manabita proyectada desde varios escenarios.

La estructura del producto turístico se describe de la siguiente manera. La primera ruta está destinada al referente cultural y al rescate tradicional de la variedad de actividades que se realizan en estas comunidades (elaboración de artesanías en barro), como recurso intangible del cantón, la misma que se estructura por la combinación de la Comunidad de Cabello y Comunidad San Miguel de Sarampión. Esta ruta ofrece servicios de alimentación, en donde destaca la gastronomía manabita, también brinda el servicio de hospedaje en la finca Sarita y la Quinta Colina del Sol. Además se brindan otras actividades, como senderismo, exposiciones de ferias gastronómicas, festivales, cosecha de productos propios de la zona, elaboración de artesanías en Zapán, tradición oral, (chigualos, amorfinos, juegos de ronda), rescate de tradiciones propias de cantón y de la zona de Manabí.

La segunda ruta enmarca el componente natural, y está constituida por las comunidades de Chapulí, Julián, La Esperanza y Primera Piedra, de las cuales se aprovechan sus potencialidades naturales en la cual se pueden realizar actividades como la pesca artesanal, el camping, canoping, escalada en las cascadas, y además se menciona un detalle para las dos rutas la proyección de la gastronomía tradicional manabita.

\section{Estructuración del PTC}

El PTC propuesto es el resultado de un estudio de mercado y está dirigido a clientes entre 18 y 30 años de edad, que busquen naturaleza y aventura, de un nivel socio eco- 
nómico medio/alto, dispuestos a caminar largas distancias donde se disfrute de la apreciación al medio ambiente, diversión, aventura y cultura. El tríptico que resume el itinerario turístico de la primera ruta diseñada y el costo del recorrido que vincula las comunidades de Cabello y Sarampión se muestra en la figura 1.

\section{FIGURA 1. Tríptico de la primera ruta del Producto Turístico "Bolívar Tesoro Escondido".}
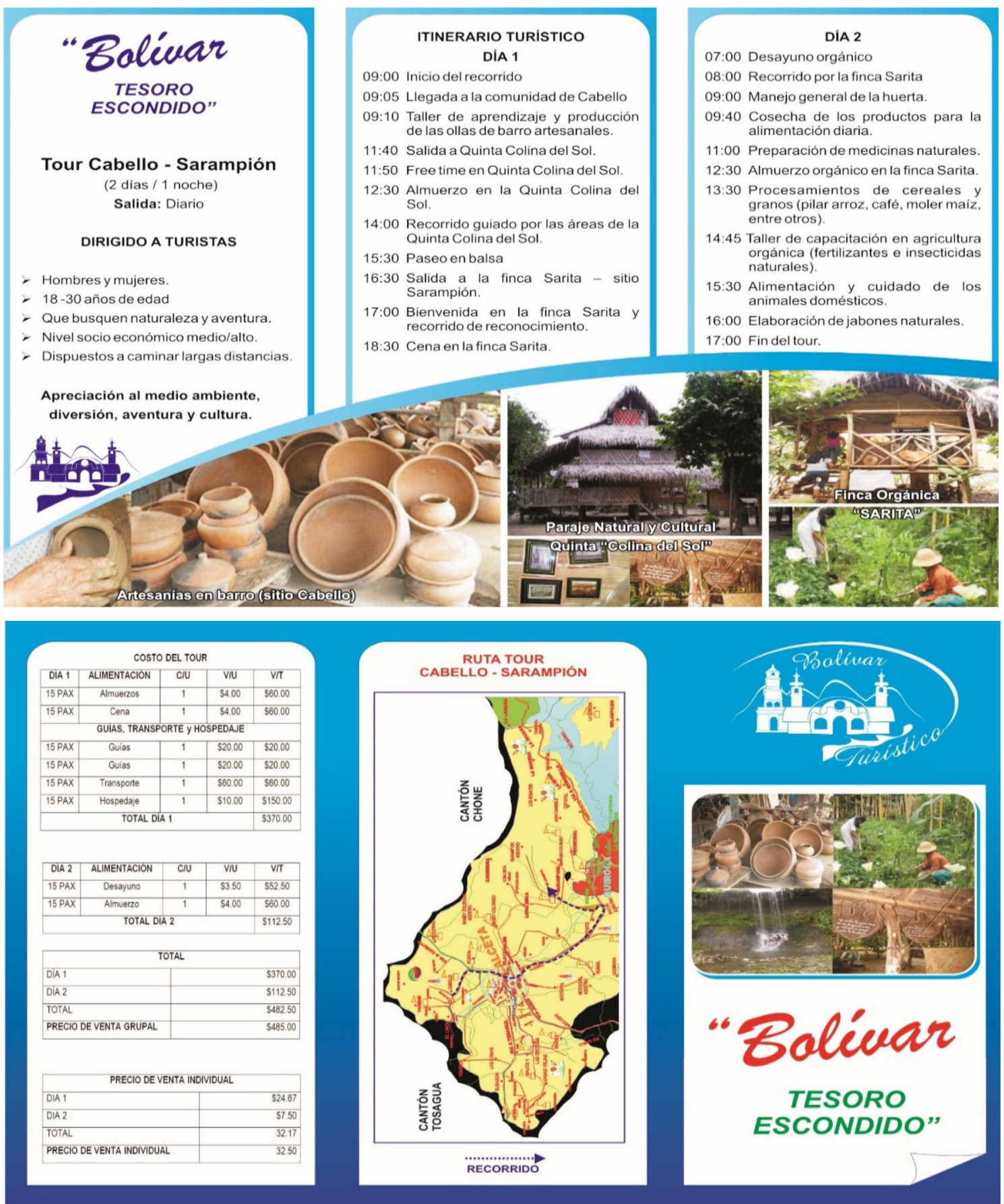
"Bolívar Tesoro Escondido" es el nombre que identifica el diseño del PTC para el cantón Bolívar. Se expresa que Bolívar es un tesoro escondido, que refleja la realidad perenne de la situación turística dentro del cantón, y si realmente es un tesoro escondido en medio del desconocimiento y la falta de aprovechamiento de todas las potencialidades que posee. El tríptico que resume el itinerario turístico de la segunda ruta diseñada y el costo del recorrido que vincula las comunidades de Chapulí, Julián, La Esperanza y Primera Piedra se muestra en la figura 2.

\section{FIGURA 2. Tríptico de la segunda ruta del Producto Turístico "Bolívar Tesoro Escondido".}

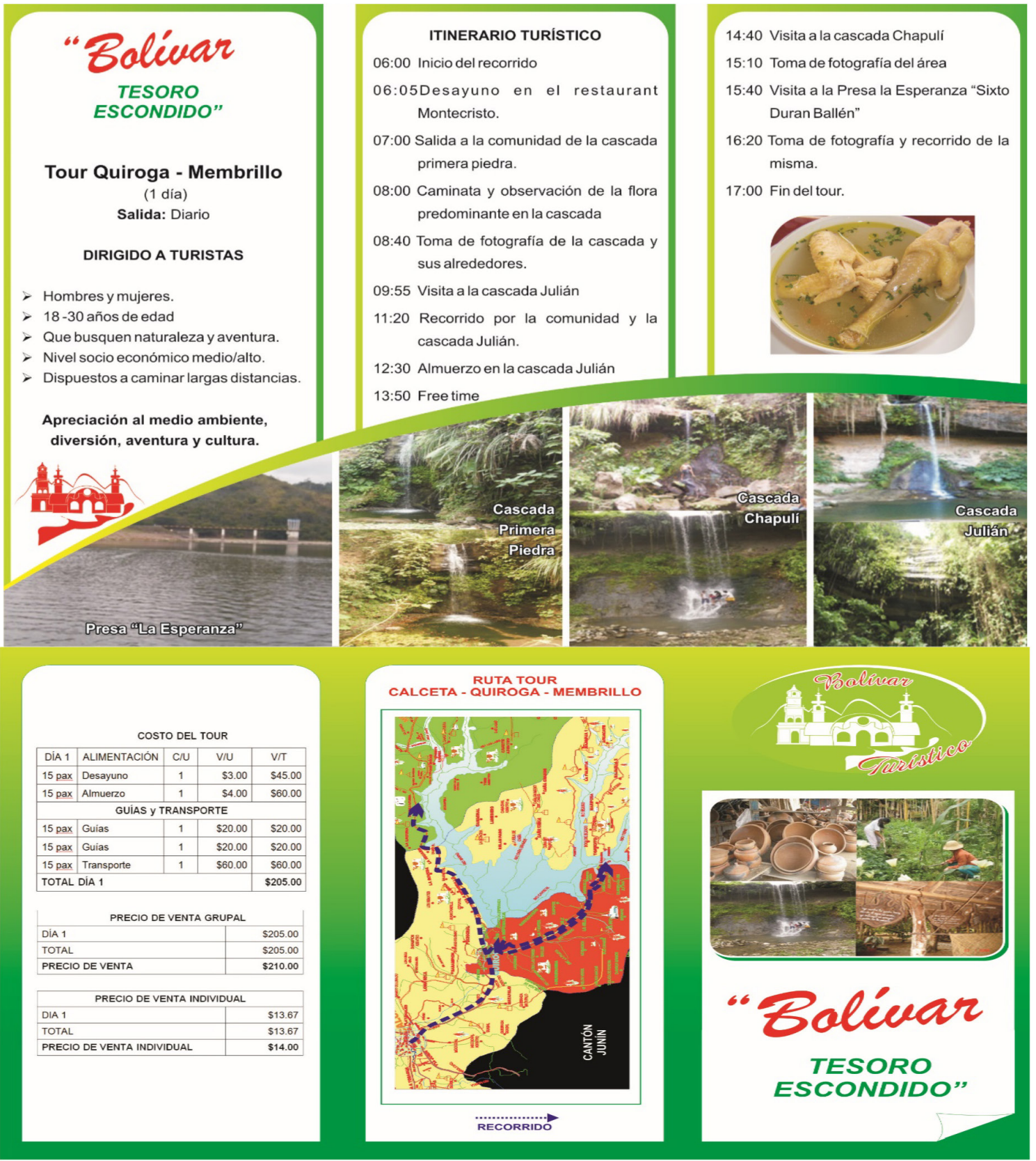




\section{Estrategias de comercialización y promoción}

Una vez diseñado el PTC compuesto por dos rutas se proponen estrategias de difusión y publicidad para su comercialización, que tomaron en cuenta la presentación del producto al mercado, mediante estrategias a desarrollar en el marketing mix, que se presentan a continuación.

- Combinación de los atractivos y facilidades identificados en las dos rutas identificadas.

- Proponer tarifas flexibles de precios acorde al periodo, los valores referenciales del mercado y la competencia.

- Alianzas estratégicas con agencias de viajes y operadores turísticos en la región.

- Comunicar beneficios de la oferta.

- Difusión del producto en medios de difusión masiva y en ferias comerciales afines.

\section{CONCLUSIONES}

Las localidades que se mencionan cuentan con un considerable potencial turístico y por ende con una variedad de recursos naturales y culturales, que de manera conjunta con las comunidades, trabajan en el fomento del desarrollo de la actividad turística comunitaria del cantón Bolívar. Existe escaso interés por las autoridades pertinentes y los gobiernos descentralizados por el aprovechamiento de los recursos turísticos que se encuentran en las áreas rurales. Los habitantes de las comunidades manifiestan interés por realizar actividades turísticas que fomenten el desarrollo de sus localidades y propicien un mejoramiento de sus condiciones de vida. La estructuración e implementación del producto turístico comunitario permite el aprovechamiento de las potencialidades turísticas del cantón Bolívar y por ende tributa al desarrollo turístico de sus comunidades.

\section{REFERENCIAS}

Aguilar, S. (2005). Fórmulas para el cálculo de la muestra en investigaciones de salud. Revista Salud en Tabasco, 11, 333-338.

Blanco, M. (2008). Guía para la elaboración del plan de desarrollo turístico de un territorio, Disponible en: http:// territorioscentroamericanos.org/sites/default/files/ Guía para elaborar el plan de desarrollo turístico de un territorio.pdf. Consultado el 10 de julio de 2016.
FEPTEC. (2013). Federación Plurinacional de Turismo Comunitario del Ecuador. Código de Operaciones de la Federación Plurinacional de Turismo Comunitario del Ecuador.

Gobierno Autónomo y Descentralizado GAD del cantón Bolívar (2011). Plan de Desarrollo y Ordenamiento Territorial del cantón Bolívar. Ecuador.

INEC (2010). Resultados del censo 2010. Instituto Nacional de Estadísticas y Censos. Disponible en http://www. ecuadorencifras.gob.ec/censo-de-poblacion-y-vivienda/. Consultado el 15 de julio de 2016.

Jurados, C. (2012). La importancia de las áreas protegidas naturales para las comunidades locales desde la perspectiva del turismo comunitario sostenible. AIDIS. Córdoba, España.

Machado, E. (2013). Integración y diseño del producto turístico aplicado a la región central del destino Cuba. GeoGraphos, 4(35), 69-92.

Machado, E., Hernández, Y. (2007). Procedimiento para el diseño de un producto turístico integrado en Cuba. Teoría y Praxis, 4, 161-174.

Maldonado, C. (2006). Turismo y comunidades indígenas: Impactos, pautas para autoevaluación y códigos de conducta. Ginebra, Suiza: Oficina Internacional del Trabajo. Disponible en http://www.ilo.org/wcmsp5/groups/public/aed_emp/aemp_ent/aifp_seed/documents/ publication/wcms_117521.pdf. Consultado el 15 de junio de 2016.

MINCETUR \& PROMPERU. (2014). Manual para la planificación de productos turísticos. Disponible en: http://www.swisscontact.org.pe/sites/default/files/ Manual\%20para\%20la\%20planificaci\%C3\%B3n\%20 de\%20productos\%20tur\%C3\%ADsticos.pdf. Consultado el 8 de julio de 2016.

Ministerio de Turismo. (2004). Metodología para inventarios de atractivos turísticos. Gerencia de Nacional de Recursos Turísticos. Quito. Ecuador. Disponible en: http:// www.turismo.gob.ec/wp- content/uploads/2015/04/ proyecto_plandetur_2011_2014VERSION2.pdf. Consultado el 14 de junio de 2016.

MINTUR. (2003). Diseño de productos turísticos del Ecuador. Disponible en: http://www.turismo.gob.ec/?s=DI- 
SE\%C3\%910+DE+PRODUCTOS+TURISTICOS+DEL+ECUADOR. Consultado el 9 de junio de 2016.

Orgaz, F. (2013). El turismo comunitario como herramienta para el desarrollo sostenible de destinos subdesarrollados. Nómadas. Revista Crítica de Ciencias Sociales y Jurídicas, 38, p. 91.

Ricaurte, C. (2009). Manual de diagnóstico turístico local. Argentina. Disponible en: http://unrn.edu.ar/blogs/
pt/files/2013/03/6-Ricaurte09-GuiaPlanTuris-ver-fichas-al-final-post-2007.pdf. Consultado el 8 de julio de 2016.

Ruiz, E., Hernández, M., Coca, A., Cantero, P., Del Campo, A. (2008). Turismo comunitario en Ecuador: Comprendiendo el community-based desde la comunidad. Pasos. Revista de Turismo y Patrimonio Cultural, 6(3), 399-418. 